\title{
Gastroesophageal Reflux Disease and Obesity: Not as Simple as We May Think
}

\author{
Joel E. Richter
}

Received: 1 May 2012/ Accepted: 8 May 2012/Published online: 4 June 2012

(C) Springer Science+Business Media, LLC 2012

There is no doubt that, over the last 20 years, westernized countries are seeing a dramatic increase in obesity [1]. This comes at the same time that we are seeing the rates of $H$. pylori infection in these populations decreasing from $80 \%$ to less than $20 \%$ [2]. Therefore, healthy stomachs with more acid and the refluxogenic contributions of obesity are together leading to an epidemic of GERD and its complications. The epidemiologic data are conclusive that obesity increases the rates of reflux symptoms, frequency and severity of esophagitis, and the frequency of Barrett's esophagus and adenocarcinoma of the esophagus [3-6]. Recent studies are also suggesting that symptom relief from proton pump inhibitors (PPIs) is more difficult to obtain in the obese patient, with more failing "on demand" therapy and single dose PPIs [7, 8]. Therefore, these patients may more frequently need to be on maintenance once or twice a day PPI regimens, possibly increasing the risk of long-term complications to this class of drugs.

What are the physiologic mechanisms by which obesity contributes to GERD? Recent studies suggest that central or abdominal obesity, as measured by the waist-to-hip ratio, may be more important than general obesity as measured by the body mass index (BMI). For example, a large cross-sectional study of 80,111 individuals from the Kaiser Permanente health system found a significant relationship between increased abdominal diameter and reflux symptoms independent of BMI (OR 1.85, $95 \%$ CI 1.55-2.21). Interestingly, this correlation was much more

J. E. Richter $(\square)$

Division of Digestive Diseases and Nutrition, Joy McCann

Culverhouse Center for Esophageal and Swallowing Disorders,

University of South Florida, Tampa, FL, USA

e-mail: jrichte1@health.usf.edu pronounced in the white population and in male subjects [9].

In theory, central obesity should raise intragastric pressure, thereby predisposing to reflux. This was proven in a seminal study by Pandolfino et al. [10] where they studied 285 patients (81 overweight: BMI $25-30 \mathrm{~kg} / \mathrm{m}^{2}$; and 75 obese: BMI $>30 \mathrm{~kg} / \mathrm{m}^{2}$ ) with high resolution manometry. They found that the pressure morphology within and across the esophagogastric junction is altered in obesity in a fashion that would promote the flow of gastric juices into the esophagus. Particularly, during the inspiratory phase of respiration, increased intragastric pressure and the gastroesophageal pressure gradient (GEPG) were strongly correlated with increased BMI. Both factors correlated even more strongly with waist circumference, suggesting that this is the mediator in the causal pathway of the BMI effect. There was a dose-dependent relationship such that the higher the BMI and waist circumference, the greater the intragastric pressure and GEPG. From an anatomic standpoint, obesity was also associated with increased axial separation between the LES and extrinsic crural diaphragm, an objective measure of the disruption of the esophagogastric junction (EGJ) culminating in the development of hiatal hernia. This confirms older studies where obesity was a significant independent risk factor for hiatal hernia, especially in whites [11]. Not to be forgotten in these mechanistic studies, a prospective study of 84 patients observed that obesity was associated with an increased frequency of transient lower esophageal sphincter relaxation and increased acid exposure [12].

Using both catheter and wireless $\mathrm{pH}$ systems, studies have shown that obesity increases acid reflux. In a crosssectional study of 206 patients, El-Serag et al. [13] found that BMI of $>30 \mathrm{~kg} / \mathrm{m}^{2}$ (compared to $<25 \mathrm{~kg} / \mathrm{m}^{2}$ ) was associated with a significant increase in acid reflux 
episodes, long reflux episodes ( $>5 \mathrm{~min}$ ), time with $\mathrm{pH}<4$ and DeMeester score. These significant associations were seen with total, postprandial, upright, and supine $\mathrm{pH}$ measurements. Using wireless $\mathrm{pH}$ technology, Crowell et al. [14] found similar findings over $48 \mathrm{~h}$ of $\mathrm{pH}$ testing in 147 subjects. Here again, acid exposure times day and night, number of acid reflux episodes, and longest episodes of esophageal acidification were significantly greater in obese subjects compared to overweight and normal weight individuals. The distinctions were even greater on the second day of $\mathrm{pH}$ monitoring, probably due to fewer restrictions on normal activity and eating patterns with this less invasive $\mathrm{pH}$ system.

In this current edition of Digestive Diseases and Sciences, Hajar et al. [15] fine-tune our understanding of the effects of obesity on all types of reflux events when patients are taking PPIs. In a retrospective review of 122 consecutive impedance-pH tests in adults (75\% overweight or obese), the total number of reflux episodes, nonacid reflex episodes ( $\mathrm{pH}$ between 4 and 7), and supine reflux episodes increased significantly as BMI increased. There was no significant difference across groups in acid reflux episodes $(\mathrm{pH}<4)$, as would be anticipated, because PPIs markedly decrease $\mathrm{pH}<4$ episodes but not total reflux events [16]. For symptoms associated with reflux (91\% of patients), the symptom index was more likely to be positive in the obese groups (normal weight $30 \%$, obese groups 51-59\%). However, symptom indices (symptom index and symptom-associated probability) can be overinterpreted unless patients have high rates of reflux, which cannot be determined from this study [17].

On the other hand, the insult at the esophagogastric junction may be more than a mechanical process. Adipose tissue is no longer considered to be an inert tissue functioning solely as energy storage, but has evolved as a critical factor in the regulation of many pathological processes. Various products of the adipose tissue have been characterized as potential adipocytokines [18]. Adipectin and leptin are the most abundant adipocytokines, but other proinflammatory cytokines produced by adipose tissue include tumor necrosis factor, interleukin 1 and 6 , and plasminogen activator inhibitor 1 [19]. These adipocytokines act systemically to influence and enhance inflammatory processes in the esophageal mucosa, negatively affect esophageal contractility leading to motor disturbances, and stimulate overall acid secretion [19]. Thus, abdominal obesity may adversely affect the esophagogastric junction both mechanically and via metabolic inflammatory pathways.

The causality between obesity and GERD is now well defined and the pathological mechanisms are being studied and better understood. The challenge is how to curtail and reverse this epidemic. The large Nurses' Health Study of over 120,000 women followed for up to 15 years gives us some reassurance that weight loss may improve GERD [20]. A weight loss of greater than $3.5 \mathrm{~kg}$ (about $8 \mathrm{lbs}$ ) reduced by nearly $40 \%$ the risk of frequent heartburn symptoms. Whether this is paralleled by decreases in the complications of GERD is not known. Furthermore, weight reduction sustained by lifestyle changes is uncommon, difficult, and unpredictable. Some of these answers may lie in careful preoperative and long-term follow-up studies of patients undergoing bariatric surgery [21].

\section{References}

1. Odgen CL, Yanovski SZ, Caroll MD, et al. The epidemiology of obesity. Gastroenterology. 2007;132:2087-2102.

2. Graham DY. The changing epidemiology of GERD: geography and H. pylori. Am J Gastroenterol. 2003;98:1462-1470.

3. El-Serag HB, Graham DY, Satia J, Rabeneck L. Obesity is an independent risk factor for GERD symptoms and erosive esophagitis. Am J Gastroenterol. 2005;100:1243-1250.

4. El-Serag HB, Kvapil P, Hacken-Bitar J, Kramer JR. Abdominal obesity and the risk of Barrett's esophagus. Am J Gastroenterol. 2005;100:2151-2156.

5. Hampel H, Abraham N, El-Serag HB. Meta-analysis: obesity and the risk of gastroesophageal reflux disease and its complications. Ann Intern Med. 2005;143:199-211.

6. Corley DA, Kubo A, Zhao W. Abdominal obesity and the risk of esophageal and gastric cardia carcinomas. Cancer Epidemiol Biomarkers Prev. 2008;17:352-358.

7. Sheu BS, Cheng HC, Chang WL, et al. The impact of body mass index on the application of on-demand therapy for Los Angeles grades A and B reflux esophagitis. Am J Gastroenterol. 2007;102: 2387-2394.

8. Chen WY, Chang WL, Tsai YC, et al. Double-dosed pantoprazole accelerates the sustained symptomatic response in overweight and obese patients with reflux esophagitis in Los Angeles A and B. Am J Gastroenterol. 2010;105:1046-1052.

9. Corley DA, Kubo A, Zhao W. Abdominal obesity, ethnicity and gastro-esophageal reflux symptoms. Gut. 2007;56:756-762.

10. Pandolfino JE, El-Serag HB, Zhang Q, et al. Obesity: a challenge to esophagogastric junction integrity. Gastroenterology. 2006; 130:639-649.

11. Wilson LJ, Ma W, Hirschowitz BI. Association of obesity with hiatal hernia and obesity. Am J Gastroenterol. 1999;94:2840 2844.

12. Wu JC, Mui M, Cheung CM, et al. Obesity is associated with increased transient LES relaxation. Gastroenterology. 2007; 132:883-889.

13. El-Serag HB, Ergun GA, Pandolfino J, et al. Obesity increases oesophageal acid exposure. Gut. 2007;56:749-755.

14. Cronwell MD, Bradley A, Hansel S, et al. Obesity is associated with increased 48-hr esophageal acid exposure in patients with symptomatic gastroesophageal reflux. Am J Gastroenterol. 2009; 104:553-559.

15. Hajar N, Castell DO, Ghomrawi H, et al. Impedance pH confirms the relationship between GERD and BMI. Dig Dis Sci. 2012. (Epub ahead of print). doi:10.1007/s10620-012-2131-6.

16. Hemmink GJM, Bredenoord AJ, Weusten BCAM, et al. Esophageal $\mathrm{pH}$-impedance monitoring in patients with therapy-resistant reflux symptoms: "On" and "off" proton pump inhibitors? Am J Gastroenterol. 2008;103:2446-2453. 
17. Slaughter JC, Goutte M, Rymer JA, et al. Caution about overinterpretation of symptom indexes in reflux monitoring for refractory reflux disease. Clin Gastroenterol Hepatol. 2011;9: 868-874.

18. Tilg H, Moschen AR. Adipocytokines: mediators linking adipose tissue inflammation and immunity. Nat Rev Immunol. 2006;6: 772-783.

19. Tilg H, Moschen AR. Visceral adipose tissue attacks beyond the liver: esophagogastric junction as a new target. Gastroenterology. 2011;139:1823-1826.
20. Jacobsen BC, Somers SC, Fuchs CS, et al. Body-mass index and symptoms of gastroesophageal reflux in women. $N$ Engl J Med. 2006;354:2340-2348.

21. Friedenberg FK, Xanthopoulos M, Foster GD, Richter JE. The association between gastroesophageal reflux disease and obesity. Am J Gastroenterol. 2008;103:2111-2122. 